\title{
ANALISIS TATA KELOLA DAN PERANCANGAN SOP SERVICE OPERATION PADA LAYANAN AKADEMIK INSTITUT PEMERINTAHAN DALAM NEGERI (IPDN) DENGAN MENGGUNAKAN FRAMEWORK ITIL VERSI 3
}

\author{
${ }^{1}$ Aridha Meitya Arifin, ${ }^{2}$ Murahartawaty, ${ }^{3}$ Ridha Hanafi \\ ${ }^{1,2,3}$ Program Studi Sistem Informasi, Fakultas Rekayasa Industri, Telkom University \\ ${ }^{1}$ aridhameitya99@gmail.com, ${ }^{2}$ murahartawaty@gmail.com, ${ }^{3}$ ridhanafi@gmail.com
}

\begin{abstract}
Abstrak-IPDN sebagai lembaga pendidikan diharapkan dapat mengikuti perkembangan teknologi informasi (TI) untuk membangun sumber daya manusia yang berkualitas serta mensinergikan kekuatan sivitas akademika IPDN. Tetapi, berdasarkan analisis kecukupan komponen tata kelola teknologi informasi dalam IT blueprint IPDN tahun 2015 - 2019, IPDN belum memiliki tata kelola TI yang memadai, sehingga manfaat teknologi informasi masih belum optimal. Penelitian ini berfokus pada domain service operation, dimana pada domain tersebut diketahui seberapa besar manfaat layanan TI. Analisis tingkat kematangan service operation kemudian dilakukan dan menunjukkan nilai maturity level yang masih berada pada level 1-initial. Berdasarkan permasalahan tersebut, kemudian dilakukan analisis risiko dan analisis prioritas terhadap tata kelola service operation sehingga hasilnya dilakukan perancangan SOP untuk dua proses dalam ITIL Versi 3 service operation yaitu manajemen insiden dan manajemen masalah. Dengan penelitian ini diharapkan dapat membantu IPDN dalam meningkatkan kapabilitas layanannya serta meningkatkan maturity level setidaknya menjadi level 3-defined.
\end{abstract}

Kata Kunci: ITIL Versi 3, Service Operation, Maturity Level, Incident Management, Problem Management, Standard Operating Procedure.

\section{PENDAHULUAN}

Teknologi informasi (TI) saat ini sudah menjadi kebutuhan yang sangat penting bagi hampir semua organisasi karena dipercaya dapat membantu meningkatkan efektifitas dan efisiensi proses tak terkecuali perguruan tinggi [1]. Oleh karena itu, pemanfaatan teknologi informasi pada bidang layanan administrasi akademik di perguruan tinggi tentunya juga menjadi suatu kebutuhan, bukan hanya sekedar prestise atau lifestyle manajemen pendidikan tinggi modern.

IPDN sebagai lembaga pendidikan diharapkan dapat mengikuti perkembangan teknologi informasi (TI) guna menunjang proses tridharma perguruan tinggi, dan membangun sumber daya manusia yang berkualitas serta mensinergikan kekuatan sivitas akademika Institut Pemerintahan Dalam Negeri. Namun, IPDN belum memiliki tata kelola TI yang memadai sehingga manfaat teknologi informasi masih belum optimal. IPDN juga dihadapkan juga pada permasalahan terbatasnya sumber daya manusia bidang TI yang tidak sebanding dengan jumlah pengguna layanan TI khususnya pada layanan akademik di IPDN. Sedangkan, penerapan TI tentunya tidak lepas dari permasalahan yang timbul pada tahap implementasi.

Dalam penelitian ini, fokus yang akan diambil yakni domain service operation, karena service operation lebih berfokus pada mengelola aktivitas harian serta penggunaan infrastruktur untuk penyampaian service, selain itu pada domain service operation inilah dimana actual value atau nilai atau manfaat nyata dari layanan TI dapat dilihat [2].

Sehingga, untuk mencapai peningkatan kapabilitas layanan, meminimalisasi insiden dan masalah yang dalam aktivitas harian layanan akademik dan pada akhirya memastikan diperolehnya value atau manfaat layanan TI bagi customer yakni sivitas akademik IPDN, maka diperlukan sebuah analisis dan rancangan terkait tata kelola service operation pada layanan akademik Institut Pemerintahan Dalam Negeri (IPDN) dengan menggunakan framework ITIL Versi 3.

\section{METODOLOGI PENELITIAN}

\section{Model Konseptual}

Model konseptual pada Gambar 1 terbagi menjadi tiga bagian yaitu input, proses, dan output. Diperlukan beberapa input untuk merancang tata kelola service operation yaitu IT Blueprint, struktur organisasi serta dokumen mengenai SIAKAD dan pengelolaan layanan atau tata kelola TI. Dari beberapa input tersebut dapat berguna dalam melakukan dua proses pada proses service operation yaitu proses perancangan incident management dan problem management. Hasilnya 
berupa dokumen SOP incident management dan SOP problem management.

\section{HASIL DAN PEMBAHASAN}

Analisis Kondisi Eksisting SIAKAD dan Tata Kelola TI IPDN Berdasarkan Literatur

Layanan Akademik dalam hal ini Sistem Informasi Akademik (SIAKAD IPDN) dikembangkan menjadi portal akademik, merupakan sebuah sistem informasi yang berfungsi sebagai integrator informasi akademik yang ada di berbagai unit akademik (program studi/fakultas dan bagian-bagian terkait) sekaligus sebagai sarana komunikasi antar civitas akademika kampus.SIAKAD perlu pengembangan lebih lanjut dalam hal implementasi di lapangan, pengembangan modul baru, integrasi dengan sistem silabus, nilai dan kuliah online, bugs fixing, peningkatan user friendly, pemutakhiran konten data dan integrasi dengan sistem pendukung. Layanan akademik ini dikelola oleh Unit Pelayanan Teknologi Informasi Komunikasi IPDN (UPTIK IPDN) [3].

Berdasarkan data yang diperoleh dari [3], diperoleh Gambaran awal kondisi eksisting tata kelola TI IPDN yang merupakan hasil analisis kecukupan komponen tata kelola TI.Dapat diketahui bahwa secara umum kondisi tata kelola teknologi informasi masih belum memadai, baik dari sisi pengambilan keputusan TI kritikal, struktur tata kelola sampai pada program tata kelola.

IPDN kemudian menuyusun rencana program terkait tata kelola TI yang dimana salah satu program yang direncanakan terkait dengan proses pada ITIL service operation yaitu pembuatan standar, prosedur dan panduan untuk incident management (manajemen insiden $\mathrm{TI}$ ) dan problem management (manajemen permasalahan TI) [3].

Analisis Tingkat Kematangan dan Analisis Kesenjangan

Penilaian kematangan dilakukan untuk Gambaran kondisi service management yang lebih mendetil dalam pemahaman dan efektivitas implementasi service management secara umum dan service operation secara khusus. Penilaian kematangan dibagi menjadi tujuh penilaian yaitu [4]:

1. Penilaian pemahaman service management sebagai sebuah practice

2. Penilaian proses - proses di dalam service operation,

3. Prinsip - prinsip dalam service operation

4. Aktivitas umum dalam service operation

5. Pengorganisasian service operation

6. Pertimbangan teknologi dalam service operation

7. Implementasi service operation.

Adapun tingkat pembobotan terdiri atas lima level, mengambil PMF atau Process Maturity Framework [5].
Masing-masing tujuh penilaian kemudian dikalkulasi dengan rumus:

$$
Z=\frac{X_{1}+X_{2}+\ldots+X_{n}}{y \cdot n}
$$

Keterangan :

$X$ : Jumlah Bobot, dimulai dari responden ke-1 sampai responden ke-n

$\mathrm{n}$ : Total responden

y : Jumlah pertanyaan kuesioner

$Z$ : Nilai rata-rata keseluruhan responden (tingkat kematangan)

Sehingga ketujuh penilaian yang telah dilakukan masingmasing memiliki level kematangan sebagai seperti yang ditunjukkan pada Gambar 2.

Berdasarkan hasil kuesioner penilaian tingkat kematangan dapat diketahui bahwa ketujuh penilaian yang dilakukan masih berada level 1-initial. Berdasarkan kesepakatan dengan stakeholder dalam hal ini organisasi UPTIK diperoleh bahwa UPTIK berharap maturity level dapat ditingkatkan menjadi level 3- defined. Perbandingan maturity level 1 dan level 3 dapat dilihat pada Tabel I.

\section{Analisis Risiko}

Assessment risiko terkait service operation dilakukan dengan mengambil jenis risiko merujukdari penelitian tentang risk management model in ITIL pada tahun 2012 [6].

Risiko TI adalah kemungkinan terjadinya threat untuk mengeksploitasi vulnerability yang ada pada aset (proses data/informasi, infrastruktur, aplikasi serta organisasi dan sumber daya manusia) dan menghasilkan dampak negatif terhadap organisasi [7]. Risiko ini perlu dikontrol agar aktivitas harian pengelolaan layanan TI atau proses dalam service operation dapat berjalan dengan baik.

Parameter untuk nilai kemungkinan (likehood) terhadap munculnya suatu risiko didasarkan antara hubungan threat (likehood of occurance) yang artinya kemungkinan terjadinya ancaman itu sendiri dengan vulnerability (ease of exploitation) yang artinya kemudahan ancaman itu terjadi dilihat dari dilaksanakan atau tidak kontrol atau aksi respon terhadap risiko yang mungkin terjadi [8]. Aset yang dinilai adalah aset yang terkait layanan akademik (Sistem Informasi Akademik IPDN), Pada Tabel II, menunjukkan risiko terkait problem management lalu risiko yang terkait dengan incident management dan event management merupakan risiko yang paling besar. 


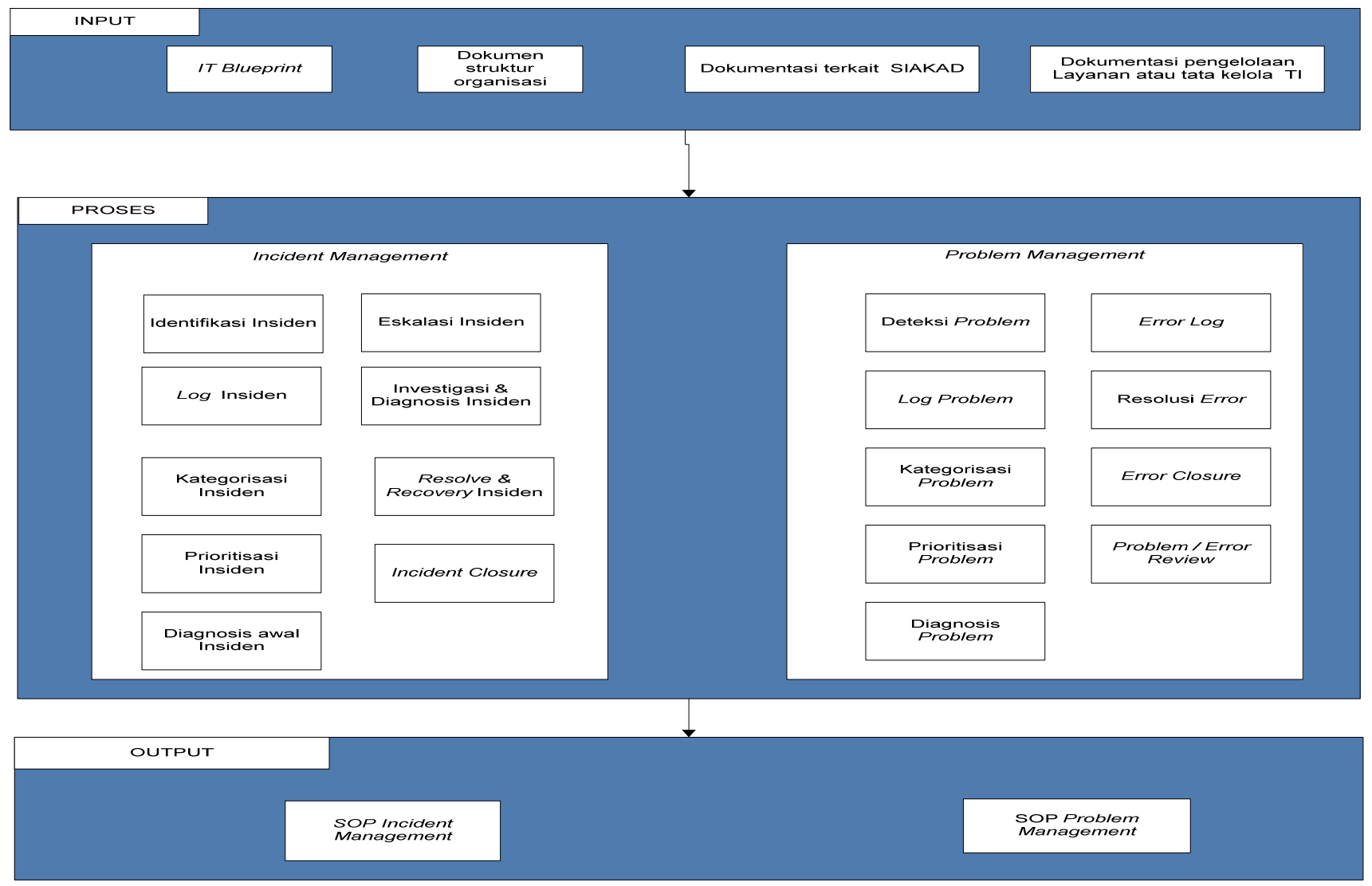

Gambar 1 Model konseptual

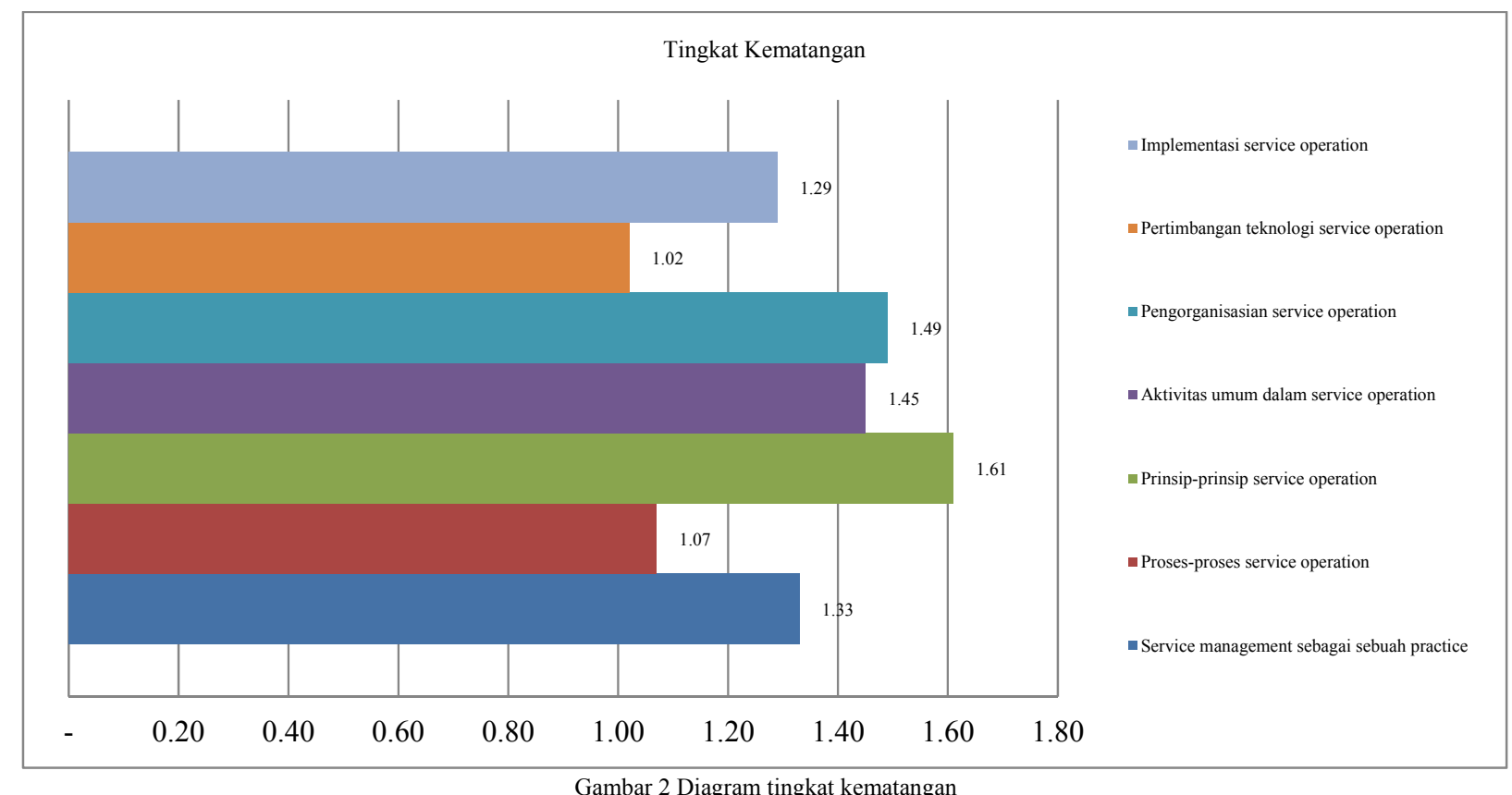

Gambar 2 Diagram tingkat kematangan 
TABELI

PERBANDINGAN MATURITY LEVEL SAAT INI DAN MATURITY LEVEL YANG DIHARAPKAN

\begin{tabular}{|c|c|c|}
\hline Dimensi yang dipertimbangkan & $\begin{array}{c}\text { Maturity level saat ini } \\
\text { (Level 1-Initial) }\end{array}$ & $\begin{array}{l}\text { Maturity level yang diharapkan } \\
\text { (Level 3-Defined) }\end{array}$ \\
\hline Vision \&Steering & $\begin{array}{l}\text { 1. Belum adanya sasaran dan } \\
\text { target formal atau indikator } \\
\text { kinerja TI yang digunakan } \\
\text { sebagai acuan pengukuran } \\
\text { performa layanan TI } \\
\text { 2. Sumber daya yang masih } \\
\text { kurang memadai } \\
\text { 3. Aktivitas yang tidak } \\
\text { terencana dan pelaporan } \\
\text { yang tidak dilakukan secara } \\
\text { rutin }\end{array}$ & $\begin{array}{l}\text { 1. Sudah terdapat sasaran dan } \\
\text { target formal atau indikator } \\
\text { kinerja TI yang } \\
\text { didokumentasikan dan disetujui } \\
\text { dan digunakan sebagai acuan } \\
\text { pengukuran performa layanan } \\
\text { TI } \\
\text { 2. Sumber daya sudah dialokasikan } \\
\text { dengan baik } \\
\text { 3. Pelaporan dan review yang } \\
\text { teratur dan terencana. }\end{array}$ \\
\hline Process & $\begin{array}{l}\text { 1. Proses dan prosedur masih } \\
\text { didefinisikan dengan } \\
\text { buruk,belum ada standar } \\
\text { proses formal } \\
\text { 2. Seluruh proses bersifat } \\
\text { reaktif terkait permasalahan } \\
\text { sehingga aktivitas dilakukan } \\
\text { secara tidak teratur atau tidak } \\
\text { terencana. }\end{array}$ & $\begin{array}{l}\text { 1. Proses dan prosedur sudah } \\
\text { didefinisikan dengan baik } \\
\text { sudahada standar proses } \\
\text { formal } \\
\text { 2. Proses sudah bersifat proaktif } \\
\text { terkait permasalahan sehingga } \\
\text { aktivitas dilakukan secara } \\
\text { sudah teratur atau terencana. } \\
\text { 3. Dokumentasi sudah dilakukan } \\
\text { dengan baik }\end{array}$ \\
\hline People & $\begin{array}{l}\text { 1. Peran dan tanggung jawab } \\
\text { belum didefinisikan dengan } \\
\text { jelas }\end{array}$ & $\begin{array}{l}\text { 1. Peran tanggung jawab } \\
\text { didefinisikan dengan jelas } \\
\text { 2. Pendefinisian secara formal } \\
\text { target pencapaian } \\
\text { 3. Formalisasi proses } \\
\text { perencanaan pelatihan }\end{array}$ \\
\hline Technology & $\begin{array}{l}\text { 1. Proses dilakukan secara } \\
\text { manual atau hanya sedikit, } \\
\text { tools yang berlainan atau tidak } \\
\text { terintegrasi. }\end{array}$ & $\begin{array}{l}\text { 1. Pengumpulan atau koleksi } \\
\text { databerkelanjutan dan } \\
\text { pelayanan aktivitas layanan } \\
\text { dengan menggunakan alarm } \\
\text { dan threshold monitoring/ } \\
\text { batasan pengawasan } \\
\text { 2. Konsolidasi data dipelihara } \\
\text { dan digunakan untuk aktivitas } \\
\text { perencanaan formal, peramalan } \\
\text { dan tren }\end{array}$ \\
\hline Culture & $\begin{array}{l}\text { 1. Penyediaan layanan } \\
\text { berorientasi pada tools dan } \\
\text { teknologi }\end{array}$ & $\begin{array}{l}\text { 1. Penyediaan layanan } \\
\text { berorientasi pada layanan dan } \\
\text { pelanggan dengan pendekatan } \\
\text { formal }\end{array}$ \\
\hline
\end{tabular}

Analisis Tata Kelola dan Perancangan SOP Service Operation pada Layanan Akademik 
TABEL II

HASIL ANALISIS RISIKO

\begin{tabular}{|c|c|c|c|}
\hline Risiko Potensial & Likehood & Impact & $\begin{array}{l}\text { Nilai } \\
\text { Risiko }\end{array}$ \\
\hline \multicolumn{4}{|l|}{ Event Management } \\
\hline $\begin{array}{l}\text { Menentukan tingkat / level yang } \\
\text { salah untuk filtering }\end{array}$ & 3 & 2 & 5 \\
\hline $\begin{array}{l}\text { Kegagalan dalam memeilihara } \\
\text { monitoring agents yang } \\
\text { diperlukan oleh seluruh IT } \\
\text { Infrastructures }\end{array}$ & 3 & 2 & 5 \\
\hline \multicolumn{4}{|l|}{ Incident Management } \\
\hline $\begin{array}{l}\text { Overflow of incidents (limpahan } \\
\text { insiden) yang tidak dapat } \\
\text { tertangani dalam skala waktu } \\
\text { yang ditetapkan karena } \\
\text { kurangnya sumber daya manusia } \\
\text { tersedia atau terlatih }\end{array}$ & 3 & 2 & 5 \\
\hline $\begin{array}{l}\text { Resolusi yang sering tertunda } \\
\text { karena inadequate support tools } \\
\text { (alat pendukung yang tidak } \\
\text { memadai) untuk memberi alert } \\
\text { dan memberi progress yang } \\
\text { cepat }\end{array}$ & 3 & 2 & 5 \\
\hline $\begin{array}{l}\text { Missmatch dalam tujuan dan } \\
\text { tindakan karena tidak adanya } \\
\text { OLAs atau UCs }\end{array}$ & 2 & 2 & 4 \\
\hline $\begin{array}{l}\text { Kurangnya sumber informasi } \\
\text { yang memadai dan / atau tepat } \\
\text { waktu karena alat yang tidak } \\
\text { memadai atau kurangnya } \\
\text { integrasi. }\end{array}$ & 3 & 2 & 5 \\
\hline \multicolumn{4}{|l|}{ Problem Management } \\
\hline $\begin{array}{l}\text { Terjadinya problem yang } \\
\text { berulang }\end{array}$ & 4 & 2 & 6 \\
\hline $\begin{array}{l}\text { Ketidakmampuan untuk } \\
\text { menggunakan previous } \\
\text { knowledge } \\
\text { ( pengetahuan sebelumnya) } \\
\text { untuk menyelesaikan problem }\end{array}$ & 4 & 2 & 6 \\
\hline $\begin{array}{l}\text { Incident Management dan } \\
\text { problem management tidak } \\
\text { saling terhubung }\end{array}$ & 3 & 2 & 5 \\
\hline \multicolumn{4}{|l|}{ Access Management } \\
\hline $\begin{array}{l}\text { Ketidakmampuan untuk } \\
\text { membatasi akses untuk } \\
\text { unauthorized users }\end{array}$ & 2 & 2 & 4 \\
\hline Sistem sulit untuk diakses & 0 & 2 & 2 \\
\hline $\begin{array}{l}\text { Ketidakmampuan untuk melacak } \\
\text { akses pengguna }\end{array}$ & 3 & 2 & 5 \\
\hline \multicolumn{4}{|l|}{ Request Fullfillment } \\
\hline $\begin{array}{l}\text { Pendefinisian ruang lingkup } \\
\text { yang buruk, yang berarti } \\
\text { orang-orang dalam } \\
\text { organisasi TI tidak } \\
\text { mengetahui dengan jelas } \\
\text { tentang proses yang } \\
\text { seharusnya ditangani } \\
\end{array}$ & 3 & 2 & 5 \\
\hline
\end{tabular}

\begin{tabular}{|l|l|l|l|}
\hline $\begin{array}{l}\text { User interfaces yang } \\
\text { didesain dan } \\
\text { dimplementasikan dengan } \\
\text { buruk sehingga users } \\
\text { mengalami kesulitan dalam } \\
\text { melakukan request }\end{array}$ & 2 & 2 & 4 \\
\hline $\begin{array}{l}\text { Buruknya desain atau } \\
\text { operasional proses back-end } \\
\text { fullfillment sehingga tidak } \\
\text { mampu menangani volume } \\
\text { dan sifat request }\end{array}$ & 2 & 2 & 4 \\
\hline $\begin{array}{l}\text { Kemampuan dalam } \\
\text { melakukan monitoring } \\
\text { (pemantauan ) yang tidak } \\
\text { memadai sehingga metrik } \\
\text { akurat tidak dapat } \\
\text { dikumpulkan }\end{array}$ & 2 & 2 & 4 \\
\hline
\end{tabular}

Rekomendasi dan Analisis Prioritas

Setelah serangkaian analisis yang telah dilakukan, diperoleh rekomendasi seperti pada Tabel III.

Lalu setelah diperoleh rekomendasi dilakukan analisis prioritas adapun dalam kasus penelitian ini, analisis prioritas bermanfaat untuk menentukan proses mana yang paling prioritas sehingga harus dilakukan proses perancangan terkait tata kelola service operation terlebih dahulu.

Prioritas ini kemudian didasarkan atas:

1. Analisis risiko

Dari analisis yang telah dilakukan risiko yang paling besar berada di proses problem management, incident management, dan event management.

2. Arahan IT Blueprint IPDN Tahun 2015-2019

Didalamnya program tata kelola IPDN tahun 2015 2019 yang mengungkapkan bahwa ada dua program utama tata kelola IPDN yang terkait service operation yaitu manajemen insiden dan manajemen masalah,

Sehingga prioritas utama yang perlu dirancang adalah:

1. Perancangan Standard Operating Procedure(SOP) untuk manajemen insiden

2. Perancangan Standard Operating Procedure (SOP) untuk manajemen rmasalah

\section{Perancangan dan Hasil}

Pembuatan Standard Operating Procedure (SOP) untuk manajemen insiden dan manajemen masalah dilakukan dengan terlebih dahulu melakukan pengambilan informasi atau penelaahan dokumen terkait tata kelola TI di IPDN serta studi literatur framework ITIL Versi 3, studi jurnal dan literatur lain yang berkaitan dengan pembuatan SOP. Dalam SOP memetakan tujuan dan proses-proses yang terdapat dalam manajemen insiden dan manajemen masalah serta memetakan struktur organisasi atau roles atau responsibilities serta mengusulkan penggunaan template yang mendukung. SOP ini kemudian diverifikasi dan divalidasi oleh pihak UPTIK IPDN. Pada Gambar 3 menunjukkan contoh screenshot dokumen SOP yang telah dibuat. 
TABEL III

REKOMENDASI

\begin{tabular}{|c|c|}
\hline Dimensi & Rekomendasi \\
\hline $\begin{array}{l}\text { Vision \& } \\
\text { Steering }\end{array}$ & $\begin{array}{l}\text { 1. Perlu adanya kebijakan Tata kelola TI dan } \\
\text { standar untuk mengukur performa penyediaan } \\
\text { layanan dan mekanisme monitoring penyediaan } \\
\text { layanan serta pelaporan kinerja layanan }\end{array}$ \\
\hline Process & $\begin{array}{l}\text { 1. Perlu adanya standard operating procedure yang } \\
\text { secara formal digunakan untuk setiap proses } \\
\text { khususnya service operation } \\
\text { 2. Perlunya sebuah dokumentasi terhadap kegiatan } \\
\text { penyediaan layanan dalam hal ini proses service } \\
\text { operation }\end{array}$ \\
\hline People & $\begin{array}{l}\text { 1. Perlu adanya mekanisme pembagian peran dan } \\
\text { tanggung jawab yang formal dengan penambahan } \\
\text { roles seperti service desk sesuai dengan arahan } \\
\text { ITIL Versi } 3 \text { Service Operation. } \\
\text { 2. Perlunya menambah sumber daya TI dalam hal } \\
\text { ini penambahan staf } \\
\text { 3. Perlu dilakukan pelatihan lebih sering untuk } \\
\text { meningkatkan skill staf UPTIK }\end{array}$ \\
\hline Technology & $\begin{array}{l}\text { 1. UPTIK perlu membangun sebuah IT Service } \\
\text { Management Application guna menunjang proses } \\
\text { penyediaan layanan }\end{array}$ \\
\hline Culture & $\begin{array}{l}\text { 1. Perlunya dibudayakan continual service } \\
\text { improvement (peningkatan layanan secara terus } \\
\text { menerus) dengan berorientasi pada kepuasaan } \\
\text { pengguna layanan }\end{array}$ \\
\hline
\end{tabular}

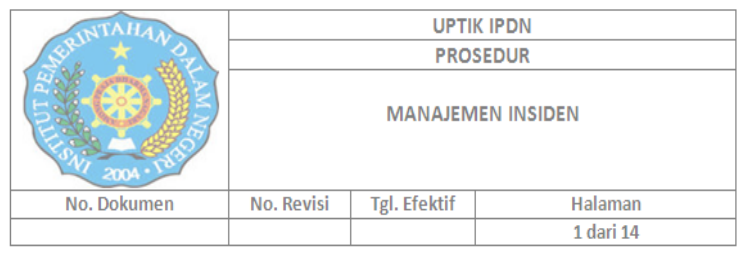

Tentang Dokumen

Dokumen ini berisi proses high level dari incident management (Manajemen Insiden).

Dokumen ini memberikan kerangka dan roadmap dari mana prosedur operasional pada proses implementasi manajemen insiden.

Setiap orang yang terlibat dalam proses ini diharapkan untuk memahami dan melaksanakan pedoman yang dijelaskan dalam dokumen ini.

Gambar 3 Screenshot dokumen standard operating procedure manajemen insiden
IV. KESIMPULAN

Penelitian ini menghasilkan dan mengusulkan dua Standard Operating Procedure (SOP) untuk manajemen insiden dan manajemen masalah. Standard operating procedure ini dapat membantu IPDN meningkatkan keberhasilan tata kelola khususnya pada dimensi proses.

IPDN perlu megimplementasikan semua rekomendasi yang diberikan karena keberhasilan tata kelola service operation, peningkatkan kapabilitas layanan dan target tingkat kematangan yakni level 3- defined dapat terpenuhi.tidak hanya ditentukan oleh adanya standard operating procedure tapi ditentukan pula oleh dimensi visi dan arahan, orang, teknologi serta budaya organisasi.

\section{DAFTAR PUSTAKA}

[1] Utomo, A. P., \& Mariana, N., Analisis Tata Kelola Teknologi Informasi ( It Governance ) pada Bidang Akademik dengan Cobit Frame Work Studi Kasus pada Universitas Stikubank Semarang, Jurnal Teknologi Informasi DINAMIK, Volume 16, Nomor 2, 2011, pp. 139 - 149.

[2] Office of Government, Introduction to ITIL Service Lifecycle, TSO, London, 2007.

[3] IT Blueprint IPDN Tahun 2015 - 2019.

[4] Radmanesh, S., Nakhaei, S., Nabhani., P. The Evaluation of Effective Elements in Information Technology Service Operation Based on ITIL Framework (Case Study: South Pars Gas Complex), Joint International Conference of Management, Knowledge and Learning (MakeLearn) and Technology, Innovation and Industrial Management (TIIM), Bari, Italia, Mei, 2015.

[5] HM Government., ITIL ® Service Design 2011 Edition, TSO, London, 2011.

[6] Real-Vilarinho, Sarah., Risk Management Model in ITIL. Dissertation, Degree of Master of Information Systems and Computer Engineering, Universidade Téchnica De Lisboa, 2012.

[7] Transforma Institute., Manajemen Risiko TI, Materi Kuliah Tata Kelola dan Manajemen TI, Universitas Telkom, Bandung, 2013.

[8] BSI., BS ISO/IEC 27005, Edisi 1, 2008.

Analisis Tata Kelola dan Perancangan SOP Service Operation pada Layanan Akademik Institut Pemerintahan Dalam Negeri (IPDN) dengan menggunakan Framework ITIL Versi 3 Aridha Meitya Arifin, Murahartawaty, Ridha Hanafi (hal.53 - 58) 